\title{
Erratum: Employing sentiment analysis for gauging perceptions of minorities in multicultural societies: An analysis of Twitter feeds on the Afrikaner community of Orania in South Africa
}

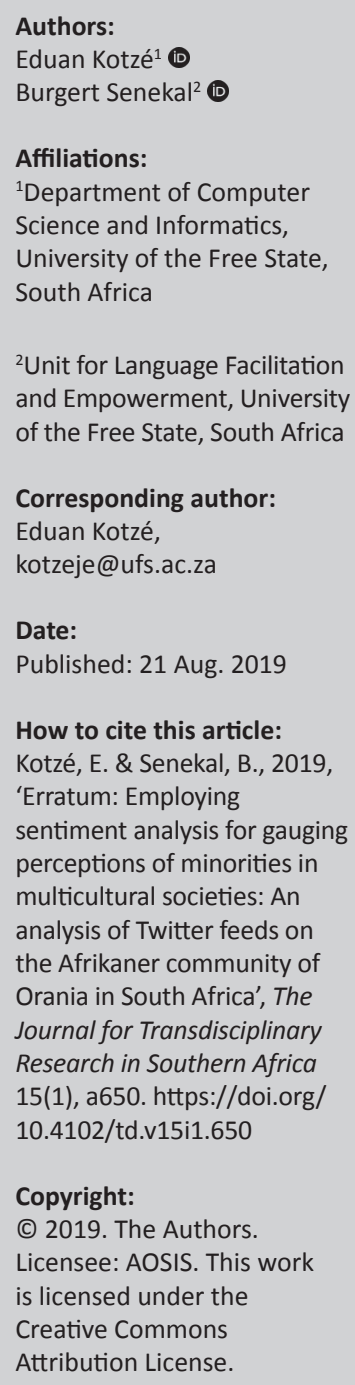

${ }^{2}$ Unit for Language Facilitation and Empowerment, University of the Free State, South Africa

Corresponding author:

Eduan Kotzé,

kotzeje@ufs.ac.za

Date:

Published: 21 Aug. 2019

How to cite this article: Kotzé, E. \& Senekal, B., 2019, 'Erratum: Employing sentiment analysis for gauging perceptions of minorities in multicultural societies: An analysis of Twitter feeds on the Afrikaner community of Orania in South Africa', The Journal for Transdisciplinary Research in Southern Africa 15(1), a650. https://doi.org/ 10.4102/td.v15i1.650

\section{Copyright:}

(c) 2019. The Authors. Licensee: AOSIS. This work

is licensed under the

Creative Commons

Attribution License.

In the version of this article initially published, the text entries in Eqn 1 and Eqn 4 were mistakenly misspelled which presented it in an illegible format. The actual values for Eqn 1 and Eqn 4 are updated and presented here:

$$
\begin{aligned}
& \text { Precision }(p)=\frac{T P}{T P+F P} \\
& F-\text { measure }=\frac{2 *(\text { Recall } * \text { Precision })}{(\text { Recall }+ \text { Precision })}
\end{aligned}
$$

These corrections do not alter the study's findings of significance or overall interpretation of the study results. The errors have been corrected in the PDF version of the article. The publisher apologises for any inconvenience caused. 